\title{
Strength evolution of cyclic loaded LSI-based C/C-SiC composites
}

\author{
Yang $\mathrm{Li}^{1,2}$, Peng Xiao ${ }^{* 1}$, Zhuan $\mathrm{Li}^{1 *}$,Wei Zhou ${ }^{1}$, Tom Liensdorf ${ }^{2}$, Wolfgang Freudenberg ${ }^{2}$, Florian \\ Reichert $^{2}$, Nico Langhof ${ }^{2}$, Walter Krenkel ${ }^{2}$ \\ ${ }^{1}$ Powder State Key Laboratory of Powder Metallurgy, Central South University, Changsha, 410083, PR China \\ ${ }^{2}$ Ceramic Materials Engineering, University of Bayreuth, Bayreuth, 95447, Germany
}

\begin{abstract}
An experimental investigation was performed to study the influence of fatigue damage introduced by different loading cycles on the residual tensile strength (RTS) of plainweave reinforced $\mathrm{C}_{\mathrm{f}} / \mathrm{C}-\mathrm{SiC}$ composites $(2 \mathrm{D} \mathrm{C} / \mathrm{C}-\mathrm{SiC}$ ). The specimens were subjected to the fatigue stress of $57 \mathrm{MPa}$ for the preselected numbers of cycles as follows: $10^{2}, 10^{4}$ and $10^{5}$, respectively, before the static tensile test. The microstructures and fractured surfaces after the tensile test were examined by optical and scanning electron microscopy, respectively. The results showed that the RTS of the specimens after the preselected fatigue cycles numbers of $10^{2}, 10^{4}$ and $10^{5}$ increase to $89.8,94.1$ and $82.4 \mathrm{MPa}$, respectively, which are somewhat higher compared to the virgin samples (79.7 $\mathrm{MPa})$. Additionally, we found that the linear part of the tensile stress-strain curve is independent on the fatigue cycles. Finally, the increased fatigue damage in $\mathrm{C} / \mathrm{C}-\mathrm{SiC}$ composites could determine a reduction of elastic modulus in all cases of fatigue tests.
\end{abstract}

Keywords: C/C-SiC; Liquid silicon infiltration; Fatigue; Cracking; Residual strength

\section{Introduction}

Currently, the liquid silicon infiltration (LSI) has proved to be one of the fully-developed methods to manufacture high performance $\mathrm{C} / \mathrm{C}$-SiC with a high efficiency and relatively low cost since 1990s [1-3]. The plain-weave carbon fabric, as one of the most common

${ }^{*}$ Corresponding author. Fax: +86 073188830131.

E-mail address: xiaopengcsu@csu.edu.cn (P.Xiao); lizhuan@csu.edu.cn (Z. Li) 
architectures of fibers, is widely applied for C/C-SiC composites (2D C/C-SiC) [4]. Comparing with the chopped fiber reinforced $\mathrm{C} / \mathrm{C}-\mathrm{SiC}$ and the non-woven fiber reinforced $\mathrm{C} / \mathrm{C}-\mathrm{SiC}$, these 2D $\mathrm{C} / \mathrm{C}-\mathrm{SiC}$ composites possess a high specific strength/modulus and a good fracture toughness and have the enormous potential for use in high performance braking systems and space structures, etc $[5,6]$. Generally, the mechanical properties of $\mathrm{C} / \mathrm{C}-\mathrm{SiC}$ composites under inevitable fluctuations in loads should be considered. Moreover, the cyclic stress could lead to the degradation of strength and catastrophic failures $[7,8]$. Hence, the study of the long-term mechanical evolution of $\mathrm{C} / \mathrm{C}-\mathrm{SiC}$ composites under complex combinations of loads is necessary. The fatigue behavior of ceramic matrix composites subjected to cyclic loadings has been studied extensively for decades [7-9]. Various analytical models including the cracking and interfacial debonding were developed to study the underlying fatigue-damage [7-11]. Additionally, our previous work has indicated that the residual tensile strength was enhanced with different previous fatigue stresses in the LSI derived C/C-SiC composites [12]. However, it is still required to understand more about the fatigue behavior of these materials. Therefore, the current work, deals with the damage-dependence of the residual tensile strength (RTS). Experimentally, the evolution of permanent strain and dynamic modulus under fatigue loading, the RTS of the specimens loaded after $10^{2}, 10^{4}$ and $10^{5}$ cycles, the microstructures and the fractured surfaces were investigated.

\section{Materials and Experimental Procedures}

The HTA carbon fiber plain-weave fabric (Toho-Tenax HTA 460-5) and a novolac resin from Hexion were used as reinforcement material and carbon precursor, respectively. The carbon fiber reinforced plastics (CFRP) for the $\mathrm{C} / \mathrm{C}-\mathrm{SiC}$ composites were fabricated by 
laminated 2D plain weave carbon fabrics. Firstly, the fabrics were pre-impregnated with a phenolic resin solution in isopropanol and dried at $20{ }^{\circ} \mathrm{C}$ for $48 \mathrm{~h}$. After stacking the fabric layers and additional phenolic resin powder, the CFRP was fabricated by a warm press process up to $170{ }^{\circ} \mathrm{C}$ for cross-linking and curing up to $300{ }^{\circ} \mathrm{C}$. The fiber volume content in the CFRP was set to around $50 \%$. Afterwards, the pyrolysis was performed in flowing nitrogen atmosphere up to $1000{ }^{\circ} \mathrm{C}$. The minimum heating rate of the pyrolysis was set to $0.5 \mathrm{~K} / \mathrm{min}$. Finally, the silicon infiltration was performed at $>1420{ }^{\circ} \mathrm{C}$ with $1 \mathrm{~h}$ dwell time under vacuum conditions.

The open porosity and bulk density of the 2D C/C-SiC composites were measured by Archimedes method in distilled water by following the DIN EN 1389. Additionally, according to the DIN EN 658-1, the static tensile tests were carried out on a Zwick/Roell test machine (Z1485, Makro, 250kN) with the dog-bone shaped specimens prepared by wire eroding as shown in the Ref [12]. Note that all specimens were cut from the same $\mathrm{C} / \mathrm{C}-\mathrm{SiC}$ plate in order to guarantee the same phase composition and same phase content in the specimens. The loading rate of the static tensile test was set to $1 \mathrm{~mm} / \mathrm{min}$. Moreover, the tensile fatigue test was conducted on a servo hydraulic testing machine (IST Hydro pulse MHF), following the ASTM C1360. All these samples with preselected number of cycles $\left(10^{2}, 10^{4}\right.$ and $10^{5}$, respectively) were performed in a strain-control mode with the following parameters: sinusoidal wave, frequency of $10 \mathrm{~Hz}$ and stress ratio of 0.1. According to the diagram of stress versus cycles to failure ( $\mathrm{S}-\mathrm{N}$ curve) of this $\mathrm{C} / \mathrm{C}-\mathrm{SiC}$ composites in the previous work [12], the maximum fatigue stress in this work was set to $57 \mathrm{MPa}$ in order to avoid failures before the completion of desired cycles. Note that the applied stress gradually increased from 0 to $57 \mathrm{MPa}$, not directly started with 57 
MPa during the fatigue test. Additionally, a period of approximately 1000 cycles was required to achieve the desired maximum stress $(57 \mathrm{MPa})$. Hence, the number of the loading cycles was started to count when the maximum stress was reached. Finally, the microstructures and fractured surfaces of the specimens were observed by an optical microscope (Axiotech HAL100, Zeiss) and a scanning electron microscope (SEM, JEOL JSM 6400).

\section{Results and Discussion}

\subsection{Fatigue behavior of 2D C/C-SiC composites}

Fig. 1(a) shows the evolution of the dynamic modulus (DM) and permanent strain (PS) during fatigue loading. Generally, higher PS corresponds with more fatigue damages within the composites [13]. As plotted in the Fig .1(a), the slope of the PS versus fatigue cycles is decreasing with the increased cycles, which indicates that the growth rate of PS gradually decreases with the increased cycles. Moreover, the decreased DM and the increased PS in the beginning are highly associated with the rapid initiation and growth of pre-existing matrix cracks, individual fiber breakage, plus an interfacial debonding $[13,14]$. Additionally, it is recommended that the initial PS within hundreds of cycles primarily result from the poor closure of extended cracks in the transverse bundles [15]. Afterwards, the progressively change of PS reveal that both, the formation and the propagation of cracks (near crack saturation) barely take place even when the specimens were loaded for $10^{5}$ cycles. As the fatigue cycling progresses, the DM is seemingly constant due to the roughly saturated fatigue damage. The fluctuation of DM is due to the open-closure effect of the cracks. Based on the different growth rates of PS during the fatigue loading, hereinafter three representative damage types induced by aforementioned 
fatigue cycles are identified to understand the effect of different fatigue damages on the RTS. Therefore, many specimens were tested for the RTS, after different amounts of preselected fatigue cycles. Fig. 1(b) presents the representative tensile stress-strain curves of a virgin and several fatigue loaded $\mathrm{C} / \mathrm{C}-\mathrm{SiC}$ specimens. The stress-strain curve of the virgin specimen substantially shows a non-linear behavior which is derived from matrix cracking and fiber breakage. In contrast, the stress-strain curves of the fatigue loaded specimens roughly show linear behaviors, when the applied stress is lower than the fatigue stress $(57 \mathrm{MPa})$. Note that the linear behavior is independent on the increasing number of the fatigue cycles beyond $10^{2}$ cycles, indicating that the cracks are already well propagated during the initial fatigue cycles. Only if the applied tensile stress is higher than $57 \mathrm{MPa}$, new damages and cracks are detectable, which corresponds with the literature, dealing with other CMC [13]. The nonlinear behavior of the fatigue loaded samples occurs with the beginning of the fiber rupture and cracking, similar to the virgin sample. Furthermore, the results of the static tensile tests of the $\mathrm{C} / \mathrm{C}-\mathrm{SiC}$ samples after $10^{2}, 10^{4}$ and $10^{5}$ cycles are summarized in Table 1.

Compared to the virgin sample, the elastic modulus for the fatigue loaded specimens are somewhat lower due to the fatigue damage. However, the elastic modulus values of the fatigue loaded specimens show seemingly no significant difference with the increasing number of fatigue cycles within the given experimental error. This could be explained by the "self-healing" effect of the composite. After the fatigue loading, the fatigue-induced cracks are partially closed, and the matrix cracks/fibers tend to move to their original places. 
However, the fatigue-induced strength enhancement can be observed beyond $10^{2}$ cycles. The mean value of RTS for the fatigue loaded specimens after $10^{2}, 10^{4}$ and $10^{5}$ loading cycles are 89.8, 94.1 and 82.4 MPa, respectively, which are somewhat higher compared to the virgin specimens. Fig. 2 shows the distribution of each RTS value for the virgin and fatigue loaded specimens. As shown in Fig. 2, it is clear that the specimens loaded after $10^{2}$ and $10^{4}$ cycles are much more focused on the high strength ranging from approximately 85-100 MPa. Hence, the trend of fatigue-induced strength enhancement could be drawn on the basis of presented data. Additionally, it is generally known that the strength enhancement or the strength degradation induced by fatigue damage is dependent on the length of fatigue period $[13,16]$. The excessive fatigue for a very long period above about $10^{5}$ cycles will undoubtedly be detrimental to the strength, even give rise to a catastrophic failure. As shown in Table 1, the initially increased fatigue damage (higher PS) could lead to more prominent effect on enhancement than degradation in RTS. However, they will reverse when the specimens subjected to the fatigue loading for a longer duration. It is shown that the RTS after $10^{4}$ cycles is higher than those of $10^{2}$ and $10^{5}$ cycles. Hence, the most pronounced effect of the fatigue damage on the RTS is seemingly obtained after $10^{4}$ cycles in current work. Predictably, as the fatigue cycle number will rise above $10^{5}$, the RTS of C/C-SiC will further decrease until the occurrence of the rupture.

\subsection{Microstructure of $\mathrm{C} / \mathrm{C}$-SiC before and after fatigue}

Fig. 3 shows the optical microstructure of $\mathrm{C} / \mathrm{C}-\mathrm{SiC}$ before and after fatigue loading. As shown in Fig. 3, the residual Si is not evenly distributed. Obviously, the most residual Si can be detected in the cross-over section between $0^{\circ}$ and $90^{\circ}$ fiber segments. The liquid $\mathrm{Si}$ 
preferentially infiltrates these pores, along with the smaller cracks which are generated during the pyrolysis of the phenolic resin. Additionally, cracks as shown in Fig. 3(a-b) should result from the mismatch of the coefficient of thermal expansion (CTE) between the fibers and matrix during the cooling from the LSI process temperature to room temperature. In general, these cracks probably extend towards to the $90^{\circ}$ orientated fibers when fatigue stress is applied. In contrast to the virgin specimens, the microstructures of the fatigue loaded specimen, as shown in Fig. 3(c-d) and Fig. 3(e-f), reveals the increased long cracks, which are bridging the adjacent $90^{\circ}$ orientated fiber bundles. The fatigue stress effectively promotes the initiation and extension of the cracks. Compared with the cracks in Fig. 3(a-b), the propagation of these fully extended cracks is stopped by the $90^{\circ}$ fibers. Therefore, these cracks are more stable and stress-insensitive, which result in progressively increased PS as shown in Fig. 1. Most importantly, the initiation and propagation of cracks in the transverse fiber bundle can effectively relieve the thermal residual stress in the composites, which enable more fiber bundles to carry the applied load uniformly and simultaneously [17].

Fig. 4 presents typical fractured surfaces and fiber/matrix interface within the specimens after the tensile tests. As shown in Fig. 4(a), the compact fiber bundles with few single fiber pull-outs and few interfacial detaching between fiber/matrix can be observed for the virgin C/C-SiC. The Fig. 4(b-d) show the fractured surface of the fatigued specimens. In contrast to Fig. 4(c-d), the fractured surface of the fatigue specimens after $10^{2}$ cycles as shown in Fig. 4(b) is somewhat different. Few interfacial debonding can be observed in Fig. 4(b), which is similar to the Fig. 4(a). The initial fatigue damages after $10^{2}$ fatigue cycles are mainly due to the matrix cracking. Significantly more single fibers and 
interfacial debonding can be observed within the pulled-out fiber bundle segments in the fractured surface of the fatigue specimens as shown in Fig. 4(c) and Fig. 4(d). Generally, more pull-out of single fibers, indicates interfacial degradation between fiber/matrix. It is known that the fatigue damage in long-term cycles is no longer just the cracking but interfacial degradation including interfacial debonding and interfacial wear. The matrix cracking initially plays a role in the strength enhancement until the cracking saturation.

At the same time, the interfacial degradation plays dual-roles in the strength enhancement and reduction as the loading cycles proceeds. On the one hand, the interfacial debonding could decrease the stress concentration in the crack tip and make a crack deflection more probable than the penetration of a crack directly into the fibers. The above-mentioned effects could lead to a finite enhancement of the fatigued loaded specimens within the short-term loading. On the other hand, the interfacial degradation, especially the interfacial wear in long term will change the interfacial sliding resistance and introduce new flaws in the fiber by means of abrasion mechanism, which are definitely detriment to the fibers and decrease the RTS. Hence, the specimens after $10^{5}$ cycles show a lower RTS than others owing to the interfacial degradation. In conclusion, the interaction of interfacial degradation and matrix cracking lead to increased fatigue damage and higher permanent strain with the increasing cycles, which make the RTS first rises in short-term (less than $10^{4}$ cycles ) then falls in the long-term (more than $10^{5}$ cycles).

\section{Conclusions}

The evolution of fatigue-induced damage subjected to the fatigue stress of $57 \mathrm{MPa}$ was characterized and the different fatigue damages were introduced by the preselected number of loading cycles $\left(10^{2}, 10^{4}\right.$ and $10^{5}$ with stress of $\left.57 \mathrm{MPa}\right)$ in order to study the 
damage-dependence of the residual tensile strength (RTS). Based on the performed investigations, following conclusions are drawn:

(1) The permanent strain gradually increased with the increasing of cycles. However, the growth rate of permanent strain gradually decreases with the increased cycles.

(2) The interaction of the matrix cracking and interfacial degradation in C/C-SiC composites under cyclic loading could determine a strength enhancement, even after for $10^{5}$ cycles. However, the maximum RTS was determined with $94.1 \mathrm{MPa}$ after $10^{4}$ cycles, which are quite higher than virgin samples (79.7 MPa).

(3) The increased fatigue damage in $\mathrm{C} / \mathrm{C}-\mathrm{SiC}$ composites could result in a reduction of elastic modulus in all cases for fatigue test.

(4) The independence of linear tensile behavior on the number of the previously loaded cycles can be observed.

\section{Acknowledgements}

The project was supported by the China Scholarship Council, the Nonferrous Metal Oriented Advanced Structural Materials and Manufacturing Cooperative Innovation Center in Central South University and the National Science Foundation of China under Grant No. 51575536 and No.51205417. Additionally, the authors would like to express the heartfelt gratitude to Mr. A. Brïckner and Mr. A. Mainz in the Department of Polymer Engineering, University of Bayreuth for their kind help with mechanical tests, to Dr. Jiang Shao-hua and Dr. LUO Heng for linguistic assistances during the preparation of this manuscript.

\section{Reference}

[1] W. Krenkel, Carbon Fiber Reinforced CMC for High-Performance Structures, International Journal of Applied Ceramic Technology, 1 (2004) 188-200.

[2] W. Krenkel, P. Schanz, Fiber ceramic structures based on liquid impregnation technique, Acta Astronautica, 28 (1992) 159-169.

[3] P. Xiao, Z. Li, X. Xiong, Microstructure and tribological properties of 3D needlepunched C/C-SiC brake composites, Solid State Sciences, 12 (2010) 617-623.

[4] W. Krenkel, R. Renz, CMCs for Friction Applications, Ceramic Matrix Composites, Wiley-VCH Verlag GmbH \& Co. KGaA2008, pp. 385-407. 
[5] W. Krenkel, F. Berndt, C/C-SiC composites for space applications and advanced friction systems, Materials Science and Engineering: A, 412 (2005) 177-181.

[6] W. Krenkel, J. Georges Thébault, Ceramic Matrix Composites for Friction Applications, Ceramic Matrix Composites, John Wiley \& Sons, Inc.2014, pp. 647-671.

[7] A.G. Evans, F.W. Zok, R.M. McMeeking, Fatigue of ceramic matrix composites, Acta Metallurgica et Materialia, 43 (1995) 859-875.

[8] P. Reynaud, Cyclic fatigue of ceramic-matrix composites at ambient and elevated temperatures, Composites Science and Technology, 56 (1996) 809-814.

[9] K.G. Dassios, D.G. Aggelis, E.Z. Kordatos, T.E. Matikas, Cyclic loading of a SiCfiber reinforced ceramic matrix composite reveals damage mechanisms and thermal residual stress state, Composites Part A: Applied Science and Manufacturing, 44 (2013) 105-113.

[10] C. Liu, L. Cheng, X. Luan, B. Li, J. Zhou, Damage evolution and real-time nondestructive evaluation of 2D carbon-fiber/SiC-matrix composites under fatigue loading, Materials Letters, 62 (2008) 3922-3924.

[11] J.W. Holmes, X. Wu, B.F. Sørensen, Frequency Dependence of Fatigue Life and Internal Heating of a Fiber-Reinforced/Ceramic-Matrix Composite, Journal of the American Ceramic Society, 77 (1994) 3284-3286.

[12] Y. Li, P. Xiao, Z. Li, W. Zhou, T. Liensdorf, W. Freudenberg, N. Langhof, W. Krenkel, Tensile fatigue behavior of plain-weave reinforced Cf/C-SiC composites, Ceramics International, 42 (2016) 6850-6857.

[13] H. Mei, L. Cheng, Stress-dependence and time-dependence of the post-fatigue tensile behavior of carbon fiber reinforced $\mathrm{SiC}$ matrix composites, Composites Science and Technology, 71 (2011) 1404-1409.

[14] G. Fantozzi, P. Reynaud, Mechanical hysteresis in ceramic matrix composites, Materials Science and Engineering: A, 521-522 (2009) 18-23.

[15] P. Reynaud, A. Dalmaz, C. Tallaron, D. Rouby, G. Fantozzi, Apparent stiffening of ceramic-matrix composites induced by cyclic fatigue, Journal of the European Ceramic Society, 18 (1998) 1827-1833.

[16] G. Fang, X. Gao, S. Zhang, J. Xue, Y. Song, F. Wang, A residual strength model for the fatigue strengthening behavior of 2D needled CMCs, International Journal of Fatigue, 80 (2015) 298-305.

[17] M. Mizuno, S. Zhu, Y. Nagano, Y. Sakaida, Y. Kagawa, M. Watanabe, CyclicFatigue Behavior of $\mathrm{SiC} / \mathrm{SiC}$ Composites at Room and High Temperatures, Journal of the American Ceramic Society, 79 (1996) 3065-3077. 
Fig. 1. (a) Permanent strain and dynamic modulus versus fatigue cycles; (b) typical tensile stress-strain curves of virgin and fatigue loaded samples.

Fig. 2. Distribution of the RTS values for the virgin and fatigue loaded specimens

Fig. 3. Typical optical microstructures of $\mathrm{C} / \mathrm{C}-\mathrm{SiC}$ (a) virgin sample ; (b) Magnification of red marked area in Fig.3 (a); (c) fatigue loaded sample after $10^{4}$ cycles; (d) Magnification of red marked area in Fig.3 (c); (e) fatigue loaded sample after $10^{5}$ cycles; (f) Magnification of red marked area in Fig.3 (e).

Fig. 4. The fracture surface of $\mathrm{C} / \mathrm{C}-\mathrm{SiC}$ composites (SEM images, topography contrast), (a) virgin sample ; (b) fatigue loaded sample after $10^{2}$ cycles; (c) fatigue loaded sample after $10^{4}$ cycles; and (d) fatigue loaded sample after $10^{5}$ cycles . 

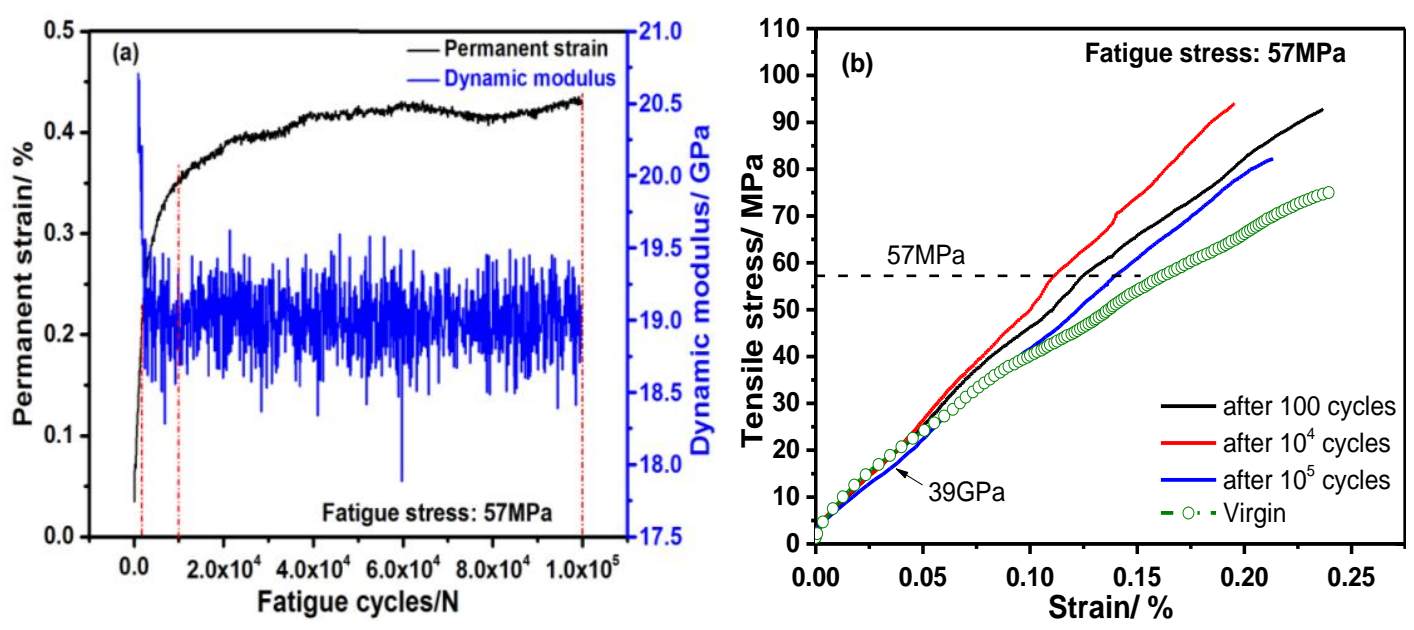

Fig. 1. (a) Permanent strain and dynamic modulus versus fatigue cycles; (b) typical tensile stress-strain curves of virgin and fatigue loaded samples. 


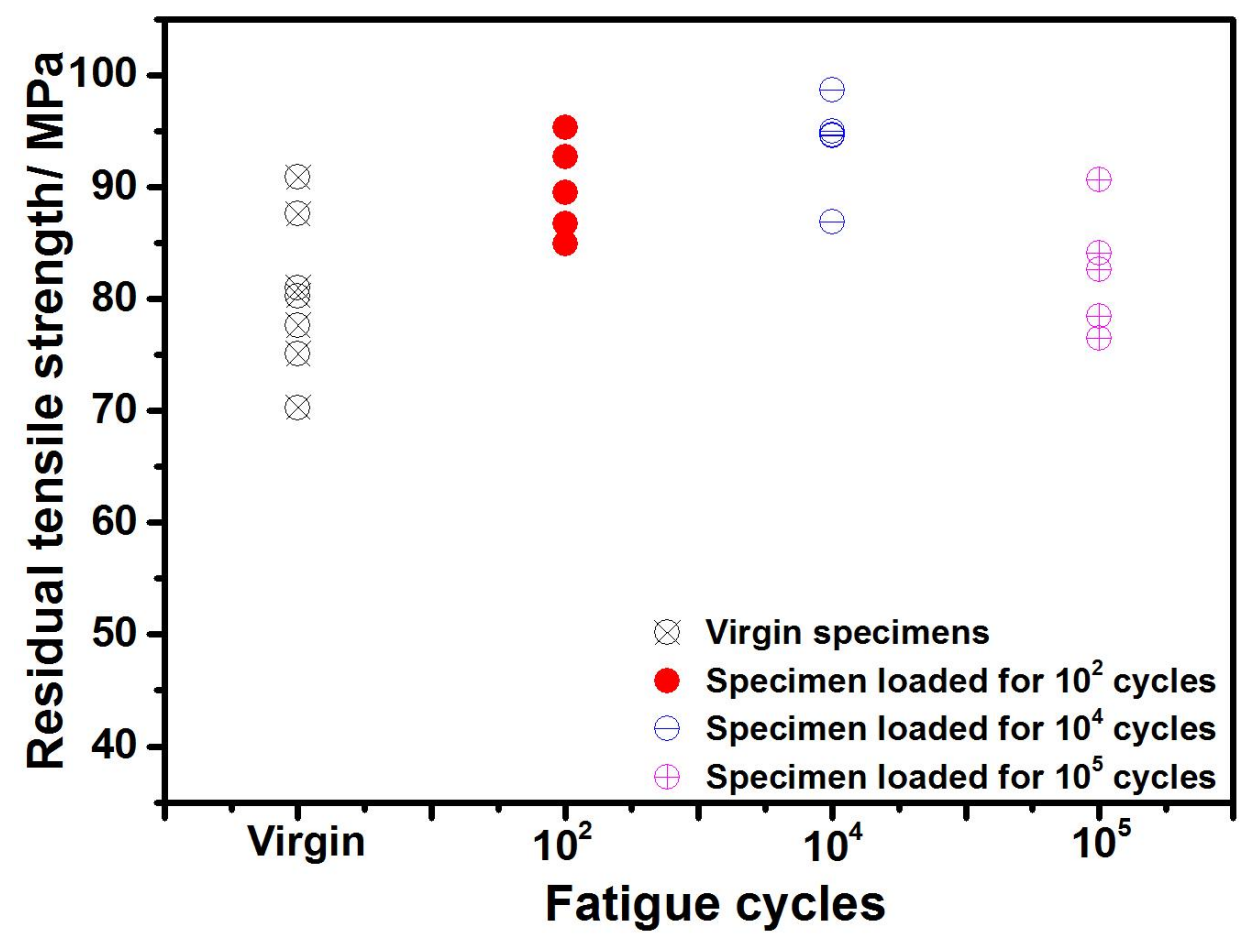

Fig. 2. Distribution of the RTS values for the virgin and fatigue loaded specimens 

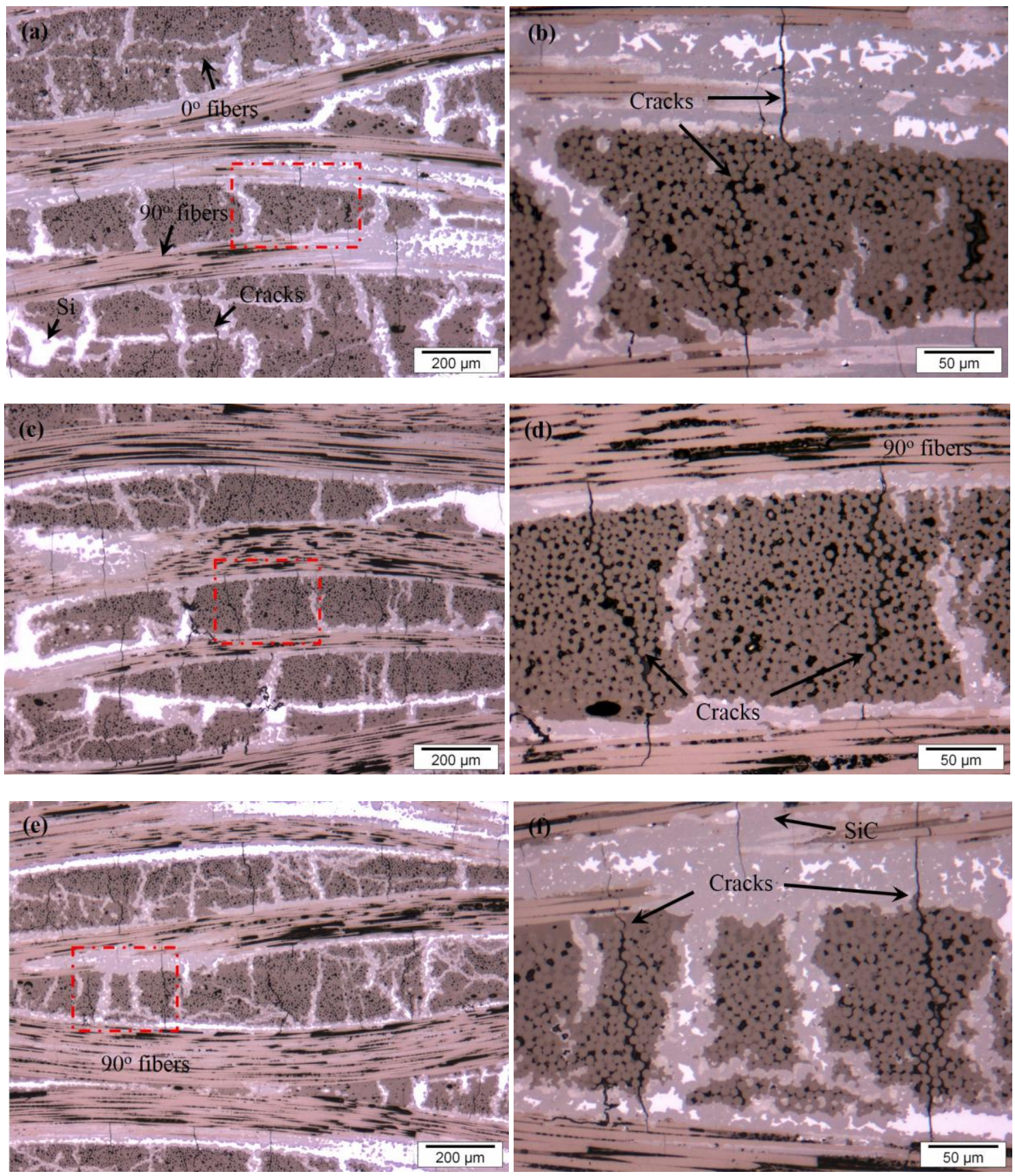

Fig. 3. Typical optical microstructures of C/C-SiC (a) virgin sample ; (b) Magnification of red marked area

in Fig.3 (a); (c) fatigue loaded sample after $10^{4}$ cycles; (d) Magnification of red marked area in Fig.3 (c); (e) fatigue loaded sample after $10^{5}$ cycles; (f) Magnification of red marked area in Fig.3 (e). 

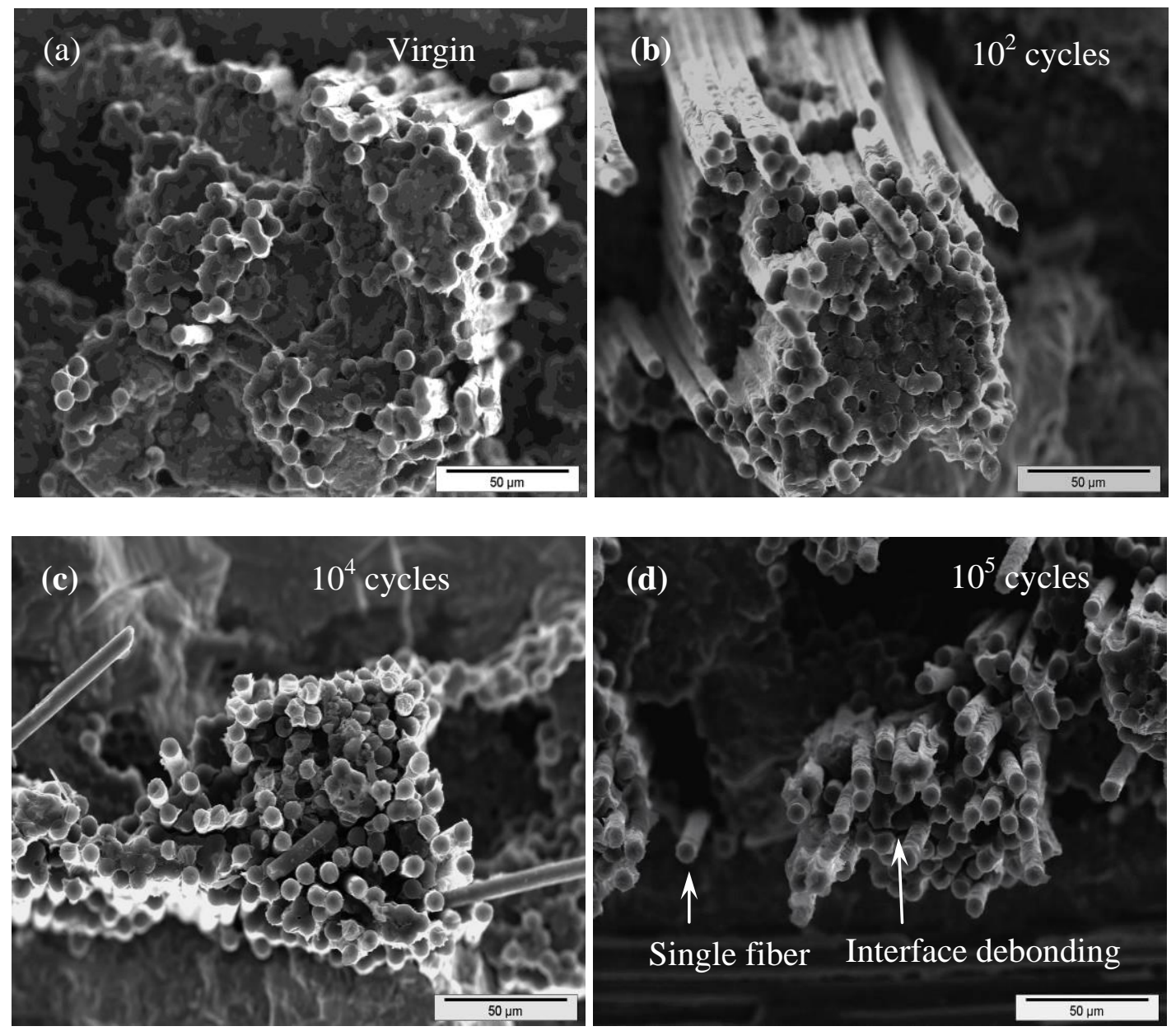

Fig. 4. The fracture surface of C/C-SiC composites (SEM images, topography contrast), (a) virgin sample ;

(b) fatigue loaded sample after $10^{2}$ cycles; (c) fatigue loaded sample after $10^{4}$ cycles; and (d) fatigue loaded sample after $10^{5}$ cycles . 
Table 1

The mechanical properties of virgin and fatigue loaded $\mathrm{C} / \mathrm{C}-\mathrm{SiC}$ composites after static tensile test 
Table 1

The mechanical properties of virgin and fatigued $\mathrm{C} / \mathrm{C}$-SiC composites after static tensile test

\begin{tabular}{lllllll}
\hline $\begin{array}{l}\text { Bulk } \\
\text { density/gcm }\end{array}$ & $\begin{array}{l}\text { Open } \\
\text { porosity\% }\end{array}$ & $\begin{array}{l}\text { Preselected } \\
\text { cycles }\end{array}$ & $\begin{array}{l}\text { Fatigue } \\
\text { stress }\end{array}$ & RTS/MPa & $\begin{array}{l}\text { Elastic } \\
\text { modulus/GPa }\end{array}$ & $\begin{array}{l}\text { Number } \\
\text { tested sample }\end{array}$ \\
\hline \multirow{3}{*}{$1.95(0.03)$} & $2.8(0.3)$ & no & no & $79.7(7.0)$ & $45.1(4.5)$ & $\mathrm{N}=7$ \\
& & $10^{2}$ & $57 \mathrm{MPa}$ & $89.8(4.2)$ & $42.3(4.1)$ & $\mathrm{N}=5$ \\
& $10^{4}$ & $57 \mathrm{MPa}$ & $94.1(4.5)$ & $40.7(3.6)$ & $\mathrm{N}=5$ \\
$\mathrm{~N}=5$ & $39.2(2.8)$ & \\
\hline
\end{tabular}

Standard deviations are given in parentheses. 